\title{
Avaliação do Potencial Energético de Bambusa vulgaris em Função da Idade
}

\author{
Ailton Teixeira do Vale ${ }^{1}$, Alessandro Cezar de Oliveira Moreira ${ }^{2}$, \\ Ildeu S. Martins ${ }^{1}$ \\ ${ }^{1}$ Departamento de Engenharia Florestal, Universidade de Brasília - UnB, Brasília/DF, Brasil \\ ${ }^{2}$ Laboratório de Produtos Florestais, Serviço Florestal Brasileiro, Brasília/DF, Brasil
}

\begin{abstract}
RESUMO
Este trabalho teve como objetivo a avaliação energética de Bambusa vulgaris ex J.C. Wendl. var. vulgaris com idades de 1, 2 e 3 anos. As amostras, provenientes de três posições ao longo do colmo (base, meio e topo), foram coletadas no plantio comercial, manejado para produção de energia, tendo os teores de material volátil, cinzas e carbono fixo; o poder calorífico superior, a densidade básica e a densidade energética; os teores de extrativos, holocelulose e lignina total determinadas. Os resultados indicam que para as idades de 1 a 3 anos houve aumento do teor de cinzas, densidade básica e energética, diminuição do teor de material volátil, de carbono fixo e de poder calorífico. Também indicam que da base para o topo houve aumento do teor de cinzas, densidade básica e energética, diminuição do teor de material volátil, de carbono fixo e do poder calorífico. Elegendo a densidade energética como a melhor variável, é possível afirmar que a qualidade da biomassa de Bambusa vulgaris como insumo energético melhora com o aumento da idade e nas porções superiores dos colmos, produzindo maior quantidade de energia por unidade de volume.
\end{abstract}

Palavras-chave: bambu, biomassa, densidade energética.

\section{Evaluation of Bambusa vulgaris Energy Potential Based on Age}

\begin{abstract}
ABSCTRACT
This study aimed to perform an energy evaluation of Bambusa vulgaris ex JC Wendl. var. vulgaris for ages 1, 2 and 3 years old. Samples from the positions along the stem (base, middle and top) were collected in commercial plantation, managed for energy production. The content of volatile material, ash and fixed carbon, high heat combustion, basic density and energy density, content of extract, holocelulose and the total lignin of B. vulgaris were determined. The results indicate that the age of 1 to 3 years old showed increased ash content, basic density and energy density, reduction of volatile material, fixed carbon content and heat combustion. And also indicate increased ash content, basic density and energy density; decreased volatile material, fixed carbon content and heat combustion from base to top. Considering the energy density as the best, we can say that the quality of Bambusa vulgaris biomass as energy input improves with increasing age and the upper portions of the stemsproduce more energy per unit volume.
\end{abstract}

Keywords: bamboo, biomass, energy density. 


\section{INTRODUÇÃO}

Segundo a Agência Internacional de Energia (IEA, 2013), o consumo mundial de insumos energéticos crescerá $40 \%$ até 2035 . Goldemberg (2010) afirma que a atual rota de desenvolvimento com base no consumo de combustíveis fósseis não é sustentável em função da exaustão das reservas, segurança de abastecimento e impactos ambientais e indica, entre outras soluções, a utilização crescente de energias renováveis. Nesse sentido, o Brasil é privilegiado, pois é considerado, segundo o Programa das Nações Unidas para o Meio Ambiente (PNUMA, 2008), o maior mercado mundial de energia renovável.

A biomassa convertida em biocombustíveis se enquadra no conceito de desenvolvimento sustentável e o bambu, como fonte de biomassa, é uma alternativa por ser, entre outros fatores, uma gramínea perene, com boa produtividade, sem necessidade de replantio (Guarnetti, 2013).

No mundo existem 1.439 espécies de bambus, distribuídas em 116 gêneros (Bamboo Phylogeny Group, 2012), com mais de 4 mil utilidades (INBAR, 2012), e o Brasil possui a maior diversidade na América Latina (Grombone-Guaratini et al., 2011). A utilização do bambu ao longo do tempo tem beneficiado o homem em várias gerações, como fonte de trabalho e renda (Almeida, 2010). No leste da Ásia, é utilizado na fabricação de casas, ferramentas agrícolas, artesanato e móveis (Negi \& Saxena, 2011). Mas, atualmente, outras frentes têm sido pesquisadas, como o uso como carvão ativado (Liu et al., 2010).

Mesmo possuindo um grande potencial industrial, o bambu ainda é pouco explorado no Brasil, por escassez de informações a seu respeito (Marinho et al., 2012). Neste sentido e com o intuito de incentivar seu cultivo no Brasil, em 8 de setembro de 2011, foi sancionada a Lei ${ }^{\circ} 12.484$, que institui a Política Nacional de Incentivo ao Manejo Sustentado e ao Cultivo do Bambu (PNMCB), que tem por objetivo o desenvolvimento da cultura do bambu no País por meio de ações governamentais e de empreendimentos privados (Brasil, 2011). Essa lei ainda não está clara no que se refere ao uso do bambu como fonte de geração de energia, mas coloca essa gramínea como uma cultura importante para o desenvolvimento econômico e social do país.
No Brasil, as espécies exóticas mais comuns são Bambusa vulgaris, Bambusa vulgaris var. vittata, Bambusa tuldoides e Dendrocalamus giganteus, todas de origem asiática trazidas pelos colonizadores portugueses e, posteriormente, o gênero Phyllostachys (Silva, 2005).

O objetivo deste trabalho foi a avaliação energética do bambu da espécie Bambusa vulgaris ex J.C. Wendl. var. vulgaris com idades de 1, 2 e 3 anos.

\section{MATERIAL E MÉTODOS}

Os bambus da espécie B. vulgaris ex J.C. Wendl. var. vulgaris utilizados para este estudo eram provenientes da plantação comercial situada em Santo Amaro (BA), onde são manejados mais de 2.000 ha, com períodos de corte de três anos, para a queima direta em processo de geração de vapor.

Os colmos foram coletados em áreas manejadas de modo que as idades das touceiras fossem conhecidas e, assim, foram utilizados colmos com idades de 1,2 e 3 anos; em cada idade, foram selecionadas três hastes, totalizando nove colmos. Cada colmo, desde seu primeiro entrenó até o último, foi segmentado nas porções base, meio e topo. As secções selecionadas foram secas naturalmente em galpão coberto e com boa circulação de ar.

Após a estabilização da umidade (12\%), procedeu-se a fragmentação e trituração das amostras em moinho do tipo Willey. Posteriormente, o produto obtido foi classificado em sistema de peneiras vibratórias, tendo sido selecionado o material passante na peneira de abertura $0,250 \mathrm{~mm}$.

Todos os ensaios foram realizados no Laboratório de Produtos Florestais (LPF), do Serviço Florestal Brasileiro (SFB), localizado em Brasília (DF), e para realização dos ensaios em que foi necessário o bambu anidro, utilizou-se a secagem em estufa de circulação forçada a uma temperatura de $105 \pm 3{ }^{\circ} \mathrm{C}$ até massa constante.

Para a realização da análise imediata, tomou-se como base a Norma Brasileira Regulamentadora (NBR) 8.112 da Associação Brasileira de Normas Técnicas (ABNT, 1986), com algumas adaptações, ao serem realizados os ensaios, a saber: amostras em triplicata e material com granulometria abaixo de $0,250 \mathrm{~mm}$, uso de cadinhos de cerâmica e, para cinzas, utilização de $2 \mathrm{~g}$ de amostra; para os voláteis, utilizou-se $1 \mathrm{~g}$ de amostra conforme estabelece a norma. 
Para a realização da análise química, utilizaram-se as metodologias da Technical Association of the Pulp and Industry: TAPPI T 204 om-88 para o teor de extrativos em etanol:tolueno (TAPPI, 1996a), TAPPI T 211 om-93 para o teor de cinzas sem extrativos a $525^{\circ} \mathrm{C}$ (TAPPI, 1996b), e as metodologias do Laboratory Analytical Procedure (LAP-003 e LAP-004) do National Renewable Energy Laboratory (NREL), para o teor de Lignina (Templeton \& Ehrman, 1995; Ehrman, 1996).

O teor de holocelulose foi determinado pela Equação 1:

$T H=100 \%-T L i g n-T C z_{525^{\circ} \mathrm{C}}$

Onde: $\mathrm{TH}=$ teor de holocelulose (\%); TLign = teor de lignina total (\%);

$\mathrm{TCz}_{525^{\circ} \mathrm{C}}=$ teor de cinzas livre de extrativos a $525^{\circ} \mathrm{C}$.

A densidade básica $\left(\rho_{\mathrm{b}}\right)$ do $B$. vulgaris obtida das regiões de amostragem foi determinada segundo a NBR 7190, ABNT (1997), pela relação entre a massa anidra e o volume saturado da amostra.

O poder calorífico superior (PCS) foi determinado para amostras anidras de aproximadamente $0,7 \mathrm{~g}$ e granulometria menor que $0,250 \mathrm{~mm}$. Os ensaios foram realizados em triplicata, com o auxílio de um calorímetro isoperibólico e metodologia descrita pela NBR 8633, ABNT (1984). A densidade energética foi determinada pela Equação 2:

$$
D E=P C S . \rho b . k
$$

em que: $\mathrm{DE}=$ densidade energética $\left(\mathrm{MJ} \mathrm{m}^{-3}\right) ; \mathrm{PCS}=$ poder calorífico superior $\left(\mathrm{kJ} \mathrm{kg}^{-1}\right) ; \rho_{\mathrm{b}}=$ densidade básica $\left(\mathrm{kg} \mathrm{m}^{-3}\right) ; k=10^{-3} \mathrm{kj}^{-1} \mathrm{Mj}$ (fator de conversão de kJ para MJ).
O experimento foi em delineamento inteiramente casualizado em arranjo fatorial, $3 \times 3$, correspondendo a três idades (1, 2 e 3 anos) e três posições no colmo (base, meio e topo), com total de nove unidades experimentais (u.e.) e nove repetições por unidade, totalizando 81 amostras. Procedeu-se à análise de variância para as características analisadas (teor dos materiais voláteis, teor de cinzas, teor de carbono fixo, densidade básica, poder calorífico superior, densidade energética, teor de extrativos totais e teor de lignina total) e teste de Tukey $(\mathrm{p} \leq 0,05)$ para a comparação entre médias dos parâmetros que apresentaram diferenças significativas pelo teste $\mathrm{F}(\mathrm{p} \leq 0,05)$. Os dados obtidos foram tratados pelo software GENES, segundo Cruz (2013).

\section{RESULTADOS E DISCUSSÃO}

Ao analisar as Tabelas 1, 2 e 3, observa-se a ocorrência de efeito significativo da idade, da posição no colmo e da interação entre idade e posição para a análise imediata, poder calorífico superior, densidades básica e energética, teores de extrativos e de lignina. Por outro lado, para os teores de carbono fixo e de holocelulose, houve efeito apenas da idade e da posição.

A diferença significativa entre as médias da maioria das variáveis estudadas é um indicativo de que há uma idade e posição mais adequada em que Bambusa vulgaris produz biomassa de melhor qualidade para fins energéticos. Essa melhor qualidade da biomassa energética está relacionada a maiores valores de carbono fixo, densidade básica, poder calorífico superior, teores de extrativos e de lignina e baixos valores de cinzas, de material volátil e holocelulose.

Para os teores de carbono fixo e holocelulose, a interação entre idades e posições no colmo não foi significativa a $5 \%$ de probabilidade, mas houve

Tabela 1. Resumo das análises de variância para material volátil, cinzas e carbono fixo de colmos de Bambusa vulgaris var. vulgaris.

Table 1. Summary of variance analyses for immediate analysis of culms of Bambusa vulgaris var. vulgaris.

\begin{tabular}{ccccc} 
Fonte de variação & Grau de liberdade & $\begin{array}{c}\text { Material volátil } \\
(\%)\end{array}$ & $\begin{array}{c}\text { Cinzas } \\
(\%)\end{array}$ & $\begin{array}{c}\text { Carbono fixo } \\
(\%)\end{array}$ \\
\hline Idade (I) & 2 & $11,91644^{*}$ & $254,93253^{*}$ & $7,04037^{*}$ \\
Posição (P) & 2 & $10,99297^{*}$ & $1800,06846^{*}$ & $38,98930^{*}$ \\
I $\times$ P & 4 & $7,69402^{*}$ & $91,06016^{*}$ & $2,30616^{\text {ns }}$ \\
Resíduo & 72 & & & 8,72966 \\
\hline $\begin{array}{c}\text { Coeficiente de } \\
\text { variação }\end{array}$ & & 2,01670 & 8,34639 & \multirow{2}{*}{} \\
\hline
\end{tabular}

${ }^{\star}$ Significativo a $5 \%$ pelo teste $\mathrm{F}$; ns: não significativo a $5 \%$ pelo teste $\mathrm{F}$. 
Tabela 2. Resumo das análises de variância para o poder calorífico superior, densidade básica e densidade energética de colmos de Bambusa vulgaris var. vulgaris.

Table 2. Values of "F" for the calorific value, basic density and energy density of culms of Bambusa vulgaris var. vulgaris.

\begin{tabular}{|c|c|c|c|c|}
\hline \multirow[b]{2}{*}{ FV } & \multirow[b]{2}{*}{ GL } & \multicolumn{3}{|c|}{ Valores de "F" } \\
\hline & & $\begin{array}{l}\text { Poder calorífico superior } \\
\qquad(\mathrm{kJ} / \mathrm{kg})\end{array}$ & $\begin{array}{c}\text { Densidade } \\
\text { básica } \\
\left(\mathrm{kg} / \mathrm{m}^{3}\right)\end{array}$ & $\begin{array}{c}\text { Densidade } \\
\text { energética }\left(\mathbf{k J} / \mathbf{m}^{3}\right)\end{array}$ \\
\hline Idade (I) & 2 & $11,09466^{*}$ & $20,15158^{*}$ & $16,05257^{\star}$ \\
\hline Posição axial (Pa) & 2 & $387,8725^{*}$ & $27,02953^{*}$ & $8,87091^{*}$ \\
\hline $\mathrm{I} \times \mathrm{Pa}$ & 4 & $30,51258^{\star}$ & $5,11667^{\star}$ & $4,49531^{\star}$ \\
\hline Resíduo & 72 & & & \\
\hline $\mathrm{CVe}$ & & 0,930727 & 8,911526 & 9,088265 \\
\hline
\end{tabular}

FV: fator de variação; GL: graus de liberdade; CVe: coeficiente de variação experimental; *significativo a 5\% (teste F); ns: não significativo a $5 \%$ (teste F).

Tabela 3. Resumo das análises de variância para a composição química imediata de colmos de Bambusa vulgaris Var. vulgaris.

Table 3. Values of "F" for immediate chemical composition of culms of Bambusa vulgaris Var. vulgaris.

\begin{tabular}{|c|c|c|c|c|}
\hline \multirow[b]{2}{*}{ FV } & \multirow[b]{2}{*}{ GL } & \multicolumn{3}{|c|}{ Valores de "F" } \\
\hline & & $\begin{array}{c}\text { Extrativos (etanol:tolueno) } \\
(\%)\end{array}$ & $\begin{array}{l}\text { Holocelulose } \\
(\%)\end{array}$ & $\begin{array}{c}\text { Lignina total } \\
(\%)\end{array}$ \\
\hline Idade & 2 & $37,87266^{*}$ & $62,67490^{*}$ & $46,60256^{*}$ \\
\hline Posição axial & 2 & $61,86278^{*}$ & $69,85375^{\star}$ & $60,54596^{*}$ \\
\hline $\mathrm{I} \times \mathrm{Pa}$ & 4 & $14,73309^{*}$ & $1,403550^{\text {ns }}$ & $6,509160^{*}$ \\
\hline Resíduo & 72 & & & \\
\hline $\mathrm{CVe}$ & & 10,726436 & 1,343901 & 3,153058 \\
\hline
\end{tabular}

FV: fator de variação; GL: graus de liberdade; CVe: coeficiente de variação experimental; * significativo a 5\% (teste F); ns: não significativo a $5 \%$ (teste $\mathrm{F})$.

diferenças significativas entre idades e posições. Assim, na Tabela 4, são apresentados os valores médios com o teste de média para o teor de carbono fixo e holocelulose, considerando a influência da idade e da posição no colmo.

Os teores médios de carbono fixo (Tabela 4) apresentaram valores decrescentes com o aumento da altura dos colmos. O teor de carbono fixo da base não diferiu do topo, assim como do meio, que também não diferiu do topo estatisticamente a $5 \%$ de probabilidade. No entanto, houve uma diferença estatística entre a base, que apresentou maior teor de carbono fixo, e o meio. Resultados semelhantes foram encontrados por Arruda \& Quirino (2008), que, ao analisarem o material da base e o do topo de Guadua magna, encontraram, respectivamente, teores de $15,67 \%$ e $14,93 \%$ de carbono fixo. Por outro lado, Aguiar \& Rousset (2010), para a espécie de B. vulgaris, verificaram, para a base, o meio e o topo, $26,22 \%, 26,47 \%$ e $27,64 \%$ de carbono fixo, respectivamente.

Foram encontrados teores de carbono fixo (Tabela 4), para as idades de 1, 2 e 3 anos, de $18,81 \%$, $18,67 \%, 15,53 \%$, respectivamente, e entre as idades de 1 e 2 anos não houve diferença estatística em nível de $5 \%$ de probabilidade, mas, entre estas e a idade de 3 anos, houve diferença estatística no mesmo nível de significância. Scurlock et al. (2000), ao estudarem a espécie Phyllostachys nigra, encontraram 16,78\%, $16,68 \%$ e $13,70 \%$, para as idades de 1,2 e 4,5 anos, revelando a mesma tendência de decréscimo no teor de carbono fixo à medida que o colmo envelhece. A tendência de decréscimo no teor de carbono fixo pode ser explicada pelo aumento dos teores de cinzas com a idade.

Os teores de holocelulose (Tabela 4) da base do colmo de Bambusa vulgaris diferiram estatisticamente ao nível de $5 \%$ de probabilidade das posições meio e 
Tabela 4. Comparação entre médias de teor de carbono fixo e teor de holocelulose.

Table 4. Tukey test for the average fixed carbon content and holocellulose content.

\begin{tabular}{|c|c|c|c|}
\hline \multicolumn{2}{|c|}{ Variáveis } & $\begin{array}{c}\text { Carbono fixo } \\
(\%)\end{array}$ & $\begin{array}{c}\text { Hololocelulose } \\
\text { (\%) }\end{array}$ \\
\hline \multirow{3}{*}{ Posição } & Base & $18,53 \mathrm{a}$ & $69,32 \mathrm{~b}$ \\
\hline & Meio & $17,13 b$ & $71,59 a$ \\
\hline & Topo & $17,31 \mathrm{ab}$ & $72,03 a$ \\
\hline \multirow{3}{*}{ Idade } & 1 ano & $18,81 \mathrm{a}$ & $70,06 \mathrm{~b}$ \\
\hline & 2 anos & $18,67 \mathrm{a}$ & $70,12 b$ \\
\hline & 3 anos & $15,53 b$ & $72,75 a$ \\
\hline
\end{tabular}

Médias seguidas da mesma letra, na coluna, não diferem entre si pelo teste de Tukey $(\mathrm{p}>0,05)$.

topo, que foram iguais estatisticamente. Colmos de $1 \mathrm{e}$ 2 anos apresentaram médias de teores de holocelulose estatisticamente iguais a $5 \%$ de probabilidade, porém diferentes dos teores apresentados pelos colmos de 3 anos de idade.

Na Tabela 5 estão os valores médios e o teste de média para as variáveis que apresentaram interação significativa ao nível de $5 \%$ de probabilidade. Analisando apenas o efeito da posição axial para colmos de Bambusa vulgaris, Moreira (2013) encontrou diferença significativa para o teor de material volátil e a posição do meio apresentou maior valor, resultado semelhante ao encontrado por Aguiar \& Rousset (2010).

O efeito isolado da idade, segundo Moreira (2013), mostra que o teor de material volátil decresce com a idade de 1, 2 e 3 anos, mas entre 1 e 2 anos não houve diferença estatística significativa a $1 \%$ de probabilidade. Scurlock et al. (2000) encontraram teores de voláteis para a espécie Phyllostachys nigra, com 1 e 2 anos, de $73,94 \%$ e $73,66 \%$.

Pelo desdobramento da interação e avaliando o efeito da idade dentro da posição axial, para materiais voláteis, observa-se que a posição de topo na idade de 3 anos apresentou o menor valor estatisticamente diferente em relação às demais idades. A avaliação do efeito da posição axial dentro da idade mostra que houve diferença estatística entre as posições apenas para a idade de 3 anos.

Moreira (2013), ao analisar isoladamente a influência da posição axial no teor de cinzas, encontrou um aumento no sentido da base para o topo do colmo, possivelmente em função da maior concentração de fibras no topo, mas entre a base e o meio do colmo os valores médios foram iguais estatisticamente ao nível de $1 \%$ de probabilidade. Aguiar \& Rousset (2010), ao estudarem a mesma espécie de bambu, encontraram resultados semelhantes com valores de 2,25\%, 2,41\%, $3,10 \%$ para a base, o meio e o topo, respectivamente. Arruda \& Quirino (2008) encontraram, para a base e o topo do bambu Guadua magna, teores de cinzas de $3,38 \%$ e $3,89 \%$, respectivamente.

Moreira (2013), ao estudar o efeito isolado da idade, encontrou valores dos teores de cinzas iguais estatisticamente ao nível de $5 \%$ de probabilidade para as idades de 1 e 2 anos, mas ambos diferiram da idade de 3 anos, evidenciando um aumento do teor de cinzas à medida que o colmo envelhece. Scurlock et al. (2000) encontraram, para a espécie Phyllostachys nigra, 0,86\% e $0,87 \%$ de teores de cinzas para as idades de 1 e 2 anos.

Observa-se pelo desdobramento da interação e avaliação do efeito da idade dentro das posições axiais para o teor de cinzas que houve diferenças estatísticas para as três posições estudadas. Nas posições base, meio e topo, os menores valores foram encontrados para a idade de 1 ano, e para as posições base e meio, o teor de cinzas não diferiu entre as idades de 1 e 2 anos. Quando se analisa o efeito da posição axial na idade, observa-se que para as idades de 2 e 3 anos há diferença estatística, com os menores valores para a posição meio na idade de 2 anos e base na idade de 3 anos.

$\mathrm{Na}$ análise do efeito isolado da posição axial no poder calorífico superior, Moreira (2013) não observou diferença estatística entre as posições base, meio e topo. O mesmo autor, ao analisar o efeito isolado da idade, concluiu que os valores médios encontrados do poder calorífico superior foram iguais estatisticamente ao nível de $5 \%$ de probabilidade entre as idades de 1 e 2 anos, e diferentes da 3 anos, e conclui afirmando que há tendência de decréscimo no poder calorífico superior 
Tabela 5. Comparação entre médias para as características que apresentaram efeito significativo da interação idade $\times$ posição axial do colmo.

Table 5. Average values and Tukey test for the characteristics that showed a significant interaction age $\times$ axial culm position.

\begin{tabular}{|c|c|c|c|c|}
\hline \multirow{2}{*}{ Propriedades } & \multirow{2}{*}{ Posição } & \multicolumn{3}{|c|}{ Idade (anos) } \\
\hline & & 1 & 2 & 3 \\
\hline \multirow{3}{*}{ Material volátil (\%) } & Base & $78,11 \mathrm{Aa}$ & $78,45 \mathrm{Aa}$ & $77,01 \mathrm{Ab}$ \\
\hline & Meio & $78,98 \mathrm{Aa}$ & $79,47 \mathrm{Aa}$ & $79,46 \mathrm{Aa}$ \\
\hline & Topo & $79,68 \mathrm{Aa}$ & $77,56 \mathrm{Aa}$ & $74,56 \mathrm{Bc}$ \\
\hline \multirow{3}{*}{$\begin{array}{c}\text { Cinzas } \\
(\%)\end{array}$} & Base & 2,33 Ba & $2,45 \mathrm{Bb}$ & $5,88 \mathrm{Ac}$ \\
\hline & Meio & $2,04 \mathrm{Ba}$ & $2,22 \mathrm{Bb}$ & $6,42 \mathrm{Ab}$ \\
\hline & Topo & $2,40 \mathrm{Ca}$ & $3,79 \mathrm{Ba}$ & $10,05 \mathrm{Aa}$ \\
\hline \multirow{3}{*}{$\begin{array}{l}\text { Poder calorífico superior } \\
\qquad(\mathrm{MJ} / \mathrm{kg})\end{array}$} & Base & $18,6 \mathrm{Aa}$ & $18,50 \mathrm{Aa}$ & $17,85 \mathrm{Aa}$ \\
\hline & Meio & $18,51 \mathrm{Aa}$ & $18,69 \mathrm{Aa}$ & $17,66 \mathrm{Ba}$ \\
\hline & Topo & $18,71 \mathrm{Aa}$ & $18,66 \mathrm{Aa}$ & $16,98 \mathrm{Bb}$ \\
\hline \multirow{3}{*}{ Densidade básica $\left(\mathrm{kg} / \mathrm{m}^{3}\right)$} & Base & $505,3 \mathrm{Bb}$ & $517,33 \mathrm{Bb}$ & $592,66 \mathrm{Ab}$ \\
\hline & Meio & $532,00 \mathrm{Bb}$ & $612,33 \mathrm{Aa}$ & $628,66 \mathrm{Ab}$ \\
\hline & Topo & $609,66 \mathrm{Ba}$ & $559,33 \mathrm{Bab}$ & $715,66 \mathrm{Aa}$ \\
\hline \multirow{3}{*}{$\begin{array}{l}\text { Densidade energética (GJ/ } \\
\left.\qquad \mathrm{m}^{3}\right)\end{array}$} & Base & 9,405 Ab & 9,57 Ab & $10,59 \mathrm{Ab}$ \\
\hline & Meio & $9,853 \mathrm{Bb}$ & $11,44 \mathrm{Aa}$ & $11,10 \mathrm{ABab}$ \\
\hline & Topo & $11,40 \mathrm{ABa}$ & $10,4 \mathrm{Bab}$ & $12,15 \mathrm{Aa}$ \\
\hline \multirow{3}{*}{$\begin{array}{l}\text { Extrativos } \\
\quad(\%)\end{array}$} & Base & $6,33 \mathrm{Aa}$ & $5,59 \mathrm{Ba}$ & $3,85 \mathrm{Cb}$ \\
\hline & Meio & $5,47 \mathrm{Ab}$ & $4,47 \mathrm{Bb}$ & $4,72 \mathrm{Ba}$ \\
\hline & Topo & $5,02 \mathrm{Ab}$ & $3,37 \mathrm{Bc}$ & $3,85 \mathrm{Bb}$ \\
\hline \multirow{3}{*}{ Lignina total (\%) } & Base & $25,32 \mathrm{Aa}$ & $26,01 \mathrm{Aa}$ & $24,94 \mathrm{Aa}$ \\
\hline & Meio & $23,59 \mathrm{Ab}$ & $24,59 \mathrm{Ab}$ & $22,40 \mathrm{Bb}$ \\
\hline & Topo & $24,08 \mathrm{Bb}$ & $25,60 \mathrm{Aab}$ & $21,99 \mathrm{Cb}$ \\
\hline
\end{tabular}

Médias seguidas das mesmas letras maiúscula, na linha, e minúscula, na coluna, não diferem entre si pelo teste de Tukey $(p>0,05)$.

com o aumento da idade, que pode estar relacionada com o aumento do teor de cinzas.

Arruda \& Quirino (2008) analisaram o poder calorífico superior da base e do topo de Guadua magna e encontraram valores de $18.610 \mathrm{~kJ} / \mathrm{kg}$ e $18.462 \mathrm{~kJ} / \mathrm{kg}$, respectivamente. Guarnetti (2013) encontrou, para Bambusa vulgaris com 2 anos de idade, nas posições base, meio e topo, respectivamente, $16.582 \mathrm{~kJ} / \mathrm{kg}, 17.221 \mathrm{~kJ} / \mathrm{kg}$ e $17.200 \mathrm{~kJ} / \mathrm{kg}$, e na idade de 3 anos, $15.457 \mathrm{~kJ} / \mathrm{kg}$, $17.150 \mathrm{~kJ} / \mathrm{kg}$ e $17.823 \mathrm{~kJ} / \mathrm{kg}$.

Observa-se pelo desdobramento da interação e avaliação do efeito da idade dentro das posições axiais para o poder calorífico superior que houve diferença estatística para as posições meio e topo. Nas posições meio e topo, os menores valores foram encontrados para a idade de 3 anos, e para as posições base, meio e topo, o poder calorífico não diferiu entre as idades de 1 e 2 anos. Quando se analisa o efeito da posição axial na idade, observa-se que, para as idades de 1 e 2 anos, não há diferença estatística. No entanto, para a idade de 3 anos, há diferença estatística significativa a $5 \%$ de probabilidade, com os menores valores para a posição topo.

Os valores médios da densidade básica indicaram um aumento da densidade da base para o topo, comportamento encontrado por outros autores, como Lima et al. (2012) que, ao estudarem duas espécies de bambus de ocorrência comum na Amazônia Ocidental, encontraram valores de densidade básica de $570 \mathrm{~kg} / \mathrm{m}^{3}$, $550 \mathrm{~kg} / \mathrm{m}^{3}$ e $590 \mathrm{~kg} / \mathrm{m}^{3}$ para B. vulgaris e valores de $400 \mathrm{~kg} / \mathrm{m}^{3}, 510 \mathrm{~kg} / \mathrm{m}^{3}$ e $550 \mathrm{~kg} / \mathrm{m}^{3}$ para Guadua sp. nas posições base, meio e topo, respectivamente. Em geral, a densidade básica aumenta com o incremento da idade da árvore (Sette et al., 2012) e, desta forma, evidencia-se um comportamento inverso da distribuição da densidade entre os bambus e a madeira. No trabalho de Moreira (2013), não foi encontrada diferença estatística em nível de 5\% de probabilidade entre as posições axiais intermediária e superior, mas, entre 
essas posições e a basal, houve diferença estatística pelo mesmo nível de significância.

A análise do desdobramento da interação para a densidade básica e o efeito da idade dentro das posições axiais indica que os maiores valores ocorreram para a idade de 3 anos. Para as posições base e topo, as densidades básicas não diferiram entre as idades de 1 e 2 anos em nível de 5\% de probabilidade, e na posição meio, as densidades básicas não diferiram entre as idades de 2 e 3 anos.

Quando se analisam o desdobramento e o efeito da posição dentro da idade, observa-se, em geral, que os maiores valores estão no topo dos colmos, com exceção da idade de 2 anos, em que ocorreu maior densidade básica na posição intermediária. Nas idades de 1 e 3 anos, as densidade de base e meio não diferiram entre si ao nível de $5 \%$ de probabilidade, enquanto, na idade de 2 anos, as posições base e topo não diferiram estatisticamente. $\mathrm{O}$ maior valor de densidade básica foi encontrado para a idade de 3 anos e posição topo.

A densidade energética média encontrada foi de $10,66 \mathrm{GJ} / \mathrm{m}^{3}$, com valores superiores ao encontrado por Protásio et al. (2013) para clones de Eucalyptus sp. com 42 meses de idade, que foi de $2,31 \mathrm{Gcal} / \mathrm{m}^{3}\left(9,65 \mathrm{GJ} / \mathrm{m}^{3}\right)$. Os valores encontrados para a densidade energética mostram tendência de aumento de 1 para 3 anos e da base para o topo. Observa-se, nas análises anteriores, uma maior variação da densidade energética com a idade e a posição axial em relação ao poder calorífico.

O desdobramento da interação e a análise da idade dentro das posições axiais mostram que para as posições da base não houve diferença significativa ao nível de 5\% de probabilidade para a densidade energética entre as idades de 1, 2 e 3 anos. Para a posição meio, as idades 1 e 2 diferem entre si ao nível de $5 \%$ de probabilidade, mas ambas não diferem da idade de 3 anos no mesmo nível de significância. Para a posição topo, as idades 2 e 3 anos diferem entre si ao nível de 5\% de probabilidade, mas ambas não diferem da idade de 1 ano no mesmo nível de significância.

A análise do desdobramento e do efeito da posição axial dentro da idade para a densidade energética mostra influência significativa das posições axiais nas idades dos colmos. Nas idades de 1, 2 e 3 anos, há diferença significativa ao nível de $5 \%$ de probabilidade para a densidade energética. Na idade de 1 ano, as posições base e meio são iguais estatisticamente. Os maiores valores estão no topo, para as idades de 1 e 3 anos, e no meio, para a idade de 2 anos.

Em geral, características como densidade e poder calorífico são utilizadas para a indicação da melhor biomassa energética ou da melhor idade de corte. No entanto, o uso de uma dessas características isoladamente pode induzir ao erro. No presente estudo, o uso do poder calorífico pode induzir a uma escolha equivocada da melhor idade de corte de Bambusa vulgaris para o uso energético (1 ou 2 anos). Quando a densidade básica é introduzida, é gerada outra variável, a densidade energética, que se apresenta como melhor opção, pois é uma característica que, ao envolver o poder calorífico e a densidade básica, leva em consideração não só as propriedades químicas, mas também as propriedades físicas da biomassa.

A composição química da biomassa influencia, de forma direta, a quantidade de energia liberada quando da queima completa desta (Huang et al., 2009; Protásio et al., 2011; Protásio et al., 2012). Assim, foram feitas a determinação e a análise dos teores de extrativos, holocelulose e lignina da biomassa.

O desdobramento da interação para o teor de extrativos mostra que, para as três posições, há influência da idade. Entre as idades de 2 e 3 anos para as posições meio e topo, não houve diferença estatística significativa ao nível de $5 \%$ de probabilidade, no entanto houve diferença dessas idades com a idade de 1 ano nas mesmas posições. Ao analisar as posições dentro das idades, observa-se uma tendência de diminuição do teor de extrativo da base para o topo com exceção da idade de 3 anos, em que o maior valor para o teor de extrativos ocorreu para a posição meio. Na idade de 1 ano, o teor de extrativos do meio e o do topo são iguais estatisticamente ao nível de $5 \%$ de probabilidade, diferindo, no entanto, da base. Na idade de 2 anos, há diferença ao nível de $5 \%$ de probabilidade entre as três posições. Na idade de 3 anos, o teor de extrativos da base é igual ao do topo, mas diferente do meio ao nível de $5 \%$ de probabilidade.

Pelo desdobramento da interação e análise da idade dentro da posição axial, quando se analisa o teor de lignina, observa-se que, para a posição base, não há influência da idade, ao contrário da posição topo, onde houve diferença estatística significativa ao nível de 5\% de probabilidade. Para a posição meio, foi encontrada diferença significativa no mesmo nível 
de significância, com a idade de 3 anos diferindo estatisticamente das idade de 1 e 2 anos, que, por sua vez, são iguais estatisticamente. A análise da posição dentro da idade mostra resultado igual para as três idades, ou seja, não há diferença estatística significativa ao nível de $5 \%$ de probabilidade entre a posição de meio e topo, mas há diferença entre estas e a base, exceto na idade de 2 anos, em que o topo também é estatisticamente igual à base ao nível de 5\% de significância.

\section{CONCLUSÕES}

Bambusa vulgaris possui características que possibilitam seu uso como combustível primário, contudo deve-se atentar para os seus altos teores de cinzas, pois estas podem vir a se fundir nas paredes das caldeiras, causando isolamento do sistema de aquecimento.

A análise isolada do poder calorífico não deve ser utilizada para a escolha de idade de corte para essa espécie nas condições de cultivo do estudo, uma vez que apresenta uma relação inversa com a idade, em função, provavelmente, do acúmulo de cinzas com envelhecimento dos colmos, para as idades estudadas. A densidade básica tem um papel importante no aumento da produção de calor por unidade de volume, mesmo com poderes caloríficos decrescentes com a idade.

A biomassa constituída de colmos de Bambusa vulgaris, sem os galhos, apresenta qualidade superior à medida que se avança da base para o topo e da idade de 1 para 3 anos. Tal constatação se dá principalmente pela análise da densidade energética que apresenta maiores valores na posição de topo e na idade de três anos.

Nesse sentido, elegendo a densidade energética como a melhor variável, é possível afirmar que a qualidade da biomassa de Bambusa vulgaris como insumo energético melhora com o aumento da idade e nas porções superiores dos colmos, produzindo maior quantidade de energia por unidade de volume.

Da idade de 1 a 3 anos, há aumento do teor de cinzas, da densidade básica e da densidade energética e diminuição do teor de material volátil, do teor de carbono fixo e do poder calorífico.

Da base para o topo do colmo, há aumento do teor de cinzas, da densidade básica e da densidade energética e diminuição do teor de material volátil, do teor de carbono fixo e do poder calorífico.

\section{AGRADECIMENTOS}

À Penha Papeis e Embalagens de Santo Amaro-BA, pela disponibilização do material para esta pesquisa e apoio logístico na coleta dos colmos de bambu.

\section{STATUS DA SUBMISSÃO}

Recebido: 26 nov., 2014

Aceito: 16 ago., 2016

\section{AUTOR(ES) PARA CORRESPONDÊNCIA}

\section{Ailton Teixeira do Vale}

Departamento de Engenharia Florestal, Universidade de Brasília - UnB, Campus Universitário Darcy Ribeiro, Asa Norte, CEP 70910-900, Brasilia, DF, Brasil e-mail: ailton.vale@gmail.com

\section{REFERÊNCIAS}

Aguiar CMD, Rousset PLA. Importância do processo de torrefação para condicionamento da biomassa do bambu para gaseificação. In: Anais do II Seminário Nacional do bambu; 2010; Rio Branco. Brasília: CPAB - Centro de pesquisa de bambu e fibras naturais; 2010, p. 72-82.

Almeida JG. Proposta para a Implantação de uma rede brasileira do bambu. In: Anais do I Seminário Nacional do Bambu; 2010; Brasília. Brasília: CPAB - Centro de pesquisa de bambu e fibras naturais; 2010; p 196.

Arruda LM, Quirino WF. Caracterização energética de bambu (Guadua magna). In: Anais do $3^{\circ}$ Cogresso Internacional de Bioenergia e Biotech Fair; 2008; Curitiba. Curitiba: Universidade Federal do Paraná; 2008.

Associação Brasileira de Normas Técnicas - ABNT. NBR-7190: determinação da densidade básica. Rio de Janeiro; 1997.

Associação Brasileira de Normas Técnicas - ABNT. NBR8112: análise imediata. Rio de Janeiro; 1986.

Associação Brasileira de Normas Técnicas - ABNT. NBR8633: determinação do poder calorífico. Rio de Janeiro; 1984.

Bamboo Phylogeny Group. An updated tribal and subtribal classification of the Bamboos (Poaceae: Bambusoideae). The Journal of the American Bamboo Society 2012; 24(1): 1-10.

Brasil. Política nacional de incentivo ao manejo sustentado e ao cultivo do bambu Lei $n^{\circ} 12.484$, de 8 de setembro de 2011. Diário Oficial da União, Brasília, DF (2011 set.).

Cruz CD. Genes: a software package for analysis in experimental statistics and quantitrative genetics. Acta 
Scientiarum. Agronomy 2013; 35: 271-276. http://dx.doi. org/10.4025/actasciagron.v35i3.21251.

Ehrman T. Chemical analysis and testing task laboratory analytical procedure LAP-004: determination of acidinsoluble lignin in biomass. Denver: National Renewable Energy Laboratory - NREL; 1996.

Goldemberg J. Energia e desenvolvimento sustentável. São Paulo: Blucher; 2010. 90 p. Série sustentabilidade n. 4.

Grombone-Guaratini MT, Nascimento AA, SantosGonçalves AP. Flowering and fruiting of Aulonemia aristulata: a gynomonoecious woody bamboo species from Atlantic Forest in Brazil. Revista Brasileira de Botanica. Brazilian Journal of Botany 2011; 34(1): 135-140. http:// dx.doi.org/10.1590/S0100-84042011000100012.

Guarnetti RL. Cogeração de eletricidade utilizando bambu no Brasil: aspectos técnicos econômicos e ambientais [tese]. São Paulo: EP/FEA/IEE/IF, Universidade de São Paulo; 2013. 156 p.

Huang C, Han L, Yang Z, Liu X. Ultimate analysis and heating value prediction of straw by near infrared spectroscopy. Waste Management 2009; 29(6): 1793-1797. http://dx.doi. org/10.1016/j.wasman.2008.11.027.

International Energy Agency - IEA. CO2 emissions from fuel combustion highlights [online]. 2013. [citado 2014 jun 12]. Disponível em: www.iea. org/publications/freepublications/publication/ CO2EmissionsFromFuelCombustionHighlights2013.pdf

International Network for for Bamboo and Rattan - INBAR. Bamboo: a new approach to carbon credits [online]. 2012. [citado 2014 jan 1]. Disponível em: http://www.inbar. int/2012/11bamboo-anew-approach-to-carbon-credits-2/

Lima DN, Afonso DG, Pontes SMA. Análise comparativa da estabilidade dimensional de 02 espécies de bambu ocorrentes na Amazônia Ocidental. In: Anais do $4^{\circ}$ Congresso Paranaense; 2012 Set 10-14; Curitiba. Curitiba: Universidade Federal de Curitiba; 2012. p. 1-10.

Liu QS, Zheng T, Wang P, Guo L. Preparation and characterization of activated carbon form bamboo by microwave-induced phosphoric acid activation. Industrial Crops and Products 2010; 31(2): 233-238. http://dx.doi. org/10.1016/j.indcrop.2009.10.011.

Marinho NP, Nisgoski N, Klock U, Andrade AS, Muñiz GIB. Análise química do bambu-gigante (dendrocalamus giganteus wall. ex munro) em diferentes idades. Ciência Florestal 2012; 22(2): 417-422. http://dx.doi. org/10.5902/198050985749.

Moreira ACO. Caracterização de Bambusa vulgaris Schard. Ex. J.C. Wendl. Var. vulgaris, e dos resíduos de caldeira no processo de conversão térmica de energia [dissertação]. Brasília: Departamento de Engenharia Florestal, Universidade de Brasília, 2013.

Negi D, Saxena S. In vitro propagation of Bambusa nutans Wall. ex Munro through axillary shoot proliferation. Plant Biotechnology 2011; 5(1):35-43. http://dx.doi.org/10.1007/ s11816-010-0154-Z.

Programa das Nações Unidas para o Meio Ambiente - PNUMA. Relatório Pnuma: tendências globais de investimentos em energias sustentáveis. 2008. [citado 2014 nov 17]. Disponível em: http://www.greenpeace.org/ brasil/Global/brasil/report/2008/7/tend-ncias-globaisde-investim.pdf

Protásio TP, Bufalino L, Tonoli GHD, Couto AM, Trugilho PF, Guimarães M Jr. Relação entre o poder calorífico superior e os componentes elementares e minerais da biomassa vegetal. Pesquisa Florestal Brasileira 2011; 31(66): 122-133.

Protásio TP, Couto AM, Reis AA, Trugilho PF. Seleção de clones de Eucalyptus para produção de carvão vegetal e bioenergia por meio de técnicas univariadas e multivariadas. Scientia Forestalis 2013; 42(97): 15-28.

Protásio TP, Trugilho PF, Neves TA, Vieira CMM. Análise de correlação canônica entre características da madeira e do carvão vegetal de Eucalyptus. Scientia Forestalis 2012; 40(95): 317-326

Scurlock JM, Dayton DC, Hames B. Bamboo: an overlooked biomass resource? Biomass and Bioenergy 2000; 19(4): 229244. http://dx.doi.org/10.1016/S0961-9534(00)00038-6.

Sette CR Jr, Oliveira IR, Tomazello M Fo, Yamaji FM, Laclau JP. Efeito da idade e posição de amostragem na densidade e características anatômicas da madeira de Eucalyptus grandis. Revista Árvore 2012; 36(6): 1183-1190. http://dx.doi.org/10.1590/S0100-67622012000600019.

Silva RMC. O bambu no Brasil e no mundo [online]. 2005. [citado em 14 out. 2011]. Disponível em http://www. embambu.com.br/imagens/bambu_brasil_mundo.pdf

Techincal Association of the Pulp and Industry - TAPPI. TAPPI test methods T 204 om-88: solvent extractives of wood and pulp. Atlanta: TAPPI Technology Park, 1996a. vol. 1.

Techincal Association of the Pulp and Industry - TAPPI. TAPPI test methods T 211 om-93: ash in wood, pulp, paper and paperboard: combustion at $525^{\circ} \mathrm{C}$. Atlanta: Tappi Technology Park, 1996b. vol. 1.

Templeton D, Ehrman T. Chemical analysis and testing task laboratory analytical procedure LAP-003: determination of acid-insoluble lignin in biomass. Denver: National Renewable Energy Laboratory - NREL; 1995. 